\title{
Parents' concerns regarding their ART children
}

\author{
L J Fisher-Jeffes, I Banerjee and A G Sutcliffe \\ Royal Free and University College Medical School, University College London, Department of Community \\ Child Health, Royal Free Campus, Rowland Hill Street, London NW3 2PF
}

Correspondence should be addressed to A G Sutcliffe; Email: a.sutcliffe@medsch.ucl.ac.uk

\begin{abstract}
A cohort of children conceived by assisted reproductive therapy (ART) - in vitro fertilisation (IVF) and intra-cytoplasmic sperm injection (ICSI) has been followed up in a National Child Development Study (Sutcliffe et al. 1999, 2001 and Bonduelle et al. 2005). Their parents were contacted and asked questions designed to elicit any concerns on their part about their child. 329 replies were received $(90 \%$ response rate), and 86 of the families posed additional questions. We found that a small number of parents $(26 \%$ of respondents) raised questions about a variety of issues regarding their ART-conceived child. The most commonly expressed theme (8\% of all respondents, or $27 / 86(31 \%)$ of the respondents with questions) pertained to their child's future fertility. This question was asked more frequently by ICSI than IVF parents.

Reproduction (2006) 131 389-394
\end{abstract}

\section{Introduction}

During recent years, studies have looked at parenting and social issues with respect to families who have conceived using assisted reproductive therapy (ART) (Golombok et al. 1995, 1996, 2001, 2002, 2004, 2005, McMahon et al. 2003, Barnes et al. 2004, Peters et al. 2005), including the parents' decision to tell their offspring of their conception (Colpin \& Soenen 2002, Lycett et al. 2004, 2005). Review articles specifically looking at this area have also been published during the past 5 years (Eugster \& Vingerhoets 1999, Fasouliotis \& Schenker 1999, Colpin 2002).

McMahon et al.1997a describes anxiety during pregnancy in IVF mothers related to their baby's survival, separation from their babies following birth, normality of their unborn babies and possible damage to their babies in childhood.

However at four months and one year post partum the separation anxiety was not significantly different from control mothers (McMahon et al. 1997b, Gibson et al. 2000b), yet it is interesting to note that this same group of IVF mothers at one year post partum considered their children as 'more vulnerable' and 'special' compared with mothers of naturally conceived children. There are no further details of why and in what way the mothers perceived their children as 'more vulnerable' and 'special'. It is possible that this perception of the parents could be related to anxiety about the health and well being of the child.

Experiences have shown that because of the 'difficult pathway' to conception, parents often have unreasonable high expectations from their child and parenthood in general. There have been reported difficulties around issues of separation and differentiation, primarily in the form of overprotection and infantilisation of the child.

Parents of ART children sometimes face problematic pregnancies compared with general population. PullanWatkins study (1987) show that stressful situation preceding or following the birth of a child, which raises concerns about health and well being of the infant, may predispose to difficult maternal child bonding. Anxious mothers may be overprotective and less able to promote autonomy development and optimal attachment.

There have been additional issues amongst these families in making the decision to tell their offspring of their conception. It has been identified that issues of identity become important in different stages of a child's life, e.g. adolescence and can give rise to parent-child conflict (Coleman \& Hendry 1990).

This experience is to a certain extent similar to those experienced by adopted children, who show increased interest in their biological origins (Hoopes 1990) around the age of 11 years. This is also the age around which this group of children demonstrate an increase in emotional and behavioural problems. Recently, several studies have looked into IVF parents' disclosure practices and attitudes (Greenfeld et al. 1996, Brewaeys et al. 1997, Colpin \& Soenen 2002, Peters et al. 2005). Most of the studies show that a large majority of parents had not yet informed their child (aged 3-10 years) at the time when the studies were done. Colpin and Soenen (2002) quote that $75 \%$ of the parents 
have not informed their children. They also comment that IVF parents who have informed their child notice significantly more difficult behaviour in their child when compared with IVF parents who have not yet disclosed mode of conception. The recent report from Peters and others (2005) stress that even though most parents had somebody (close friend, family), only $26 \%$ mothers and $17 \%$ fathers had discussed mode of conception with child. However they also point out that $58 \%$ of mothers $57 \%$ of fathers intended to tell their child at some point.

There is, however no report describing parental concern about their ART conceived child's future health and wellbeing, although several studies on mother-child relationships (Gibson et al. 2000, Hahn \& DiPietro 2001) describes parental over protectiveness. It could be valuable to practitioners caring for families who have had fertility treatment to have information on what sort of concerns their clients may have. We thought it would be useful to enquire from our National Child Development study families (Sutcliffe et al. 1999, 2001, 2005) if they had any concerns about their child's present and future health and development.

\section{Materials and Methods}

North Thames MREC has given ethical approval for our ongoing National Child Development Study, comparing the general health and development of children who have been conceived by IVF and ICSI to that of age-matched naturally conceived controls.

Families were recruited from 22 UK fertility units and these children (now 8-9 years old) were assessed for growth and development at approximately 5 years of age. This study will follow these children up until adulthood with regular contact by post and occasional assessments.

Families were contacted initially by post. Parents who did not respond to the first letter were sent a reminder, and those who still did not respond were contacted by telephone. They were asked if they would be willing to complete the questionnaire by telephone interview.

A letter was sent to update parents on study progress and promised to send them the results of our evaluation at 5 years, once they were ready for publication. Enclosed was a short questionnaire (see Fig. 1) with tick boxes for them to indicate whether they felt monitoring of child growth and development, and/or the investigation of future possible risk of health problems in children conceived by ART was important to them. We asked them to indicate whether they would be interested in participating in further studies in these areas, and then asked them if they had any further questions that could be answered in future studies. A prepaid addressed envelope was enclosed for them to reply, and

\section{Survey questionnaire}

Dear Parents

Could you please tick which of the following areas, you think may be important regarding children who have been conceived with extra help. Little is known about these areas. We can only find answers with the cooperation of families, with children such as your own.

1. Monitoring of general child development
(We have done this to age of 5 but feel this need
to continue)
2. Monitoring of child physical development
3. Investigating the future possible risk of health
problems in children as they grow up
Are there any questions that you would like the
answers to that we may be able to investigate in
the type of studies we have carried out so far?

- If parents express interest in particular subjects we will write again, depending on your responses. All correspondence will continue to be strictly confidential.

- Please note that we have no evidence that any of these areas may be a problem in the future but having been approached by parents concerned about possibilities, we felt we should ask you your views.

Figure 1 Sample of questions used in questionnaire sent to parents. 
Table 1 Range of questions asked by ART parents.

\begin{tabular}{lcrr}
\hline Question theme & $\begin{array}{c}\text { Total no of respondents } \\
\text { who asked }\end{array}$ & ICSI & IVF \\
\hline Their child's future fetility & $27(8 \%)$ & 20 & 7 \\
General health & $12(3.6 \%)$ & 4 & 8 \\
How to tell the child & $11(3.3 \%)$ & 6 & 5 \\
Anxieties raised by press articles & $7(2 \%)$ & 1 & 6 \\
Risks to embryo cryopreservation & $6(1 \%)$ & 0 & 6 \\
Education potential/learning & $6(1 \%)$ & 3 & 3 \\
$\quad$ difficulty & & & \\
ADHD/hyperactivity & 4 & 3 & 1 \\
Personality/social skills & 4 & 1 & 3 \\
Development (non-specific) & 3 & 2 & 1 \\
Dyslexia & 3 & 3 & 0 \\
Are ART parents overprotective & 2 & 0 & 2 \\
Genetic disorders & 2 & 0 & 2 \\
Leukaemia & 2 & 0 & 2 \\
Urinary tract infections & 2 & 0 & 2 \\
Short stature & 2 & 1 & 1 \\
Weight gain & 1 & 1 & 0 \\
Visual-perceptual difficulties & 1 & 1 & 0 \\
Autistic spectrum disorder & 1 & 1 & 0 \\
Hearing & 1 & 1 & 0 \\
GORD & 1 & 0 & 1 \\
Food allergy & 1 & 1 & 0 \\
Chest problems & 1 & 0 & 1 \\
Painful genitalia & 1 & 1 & 0 \\
Asthma & 1 & 1 & 0 \\
Rheumatic disorders & 1 & 0 & 1 \\
Loose-jointedness & 1 & 1 & 0 \\
Encephalitis & 1 & 0 & 1 \\
Prematurity & 1 & 53 & 53 \\
Totals & 106 & & \\
\hline A & & & \\
\hline
\end{tabular}

ART, assisted reproductive therapy; ICSI, intracytoplasmic sperm injection; IVF, in vitro fertilization; ADHD, attention deficit hyperactivity disorder; GORD, gastroesophageal reflux disease. they were asked to inform us of any future address changes.

\section{Results}

The parents of 362 children were contacted, 186 whom had conceived by ICSI, and 176 who had conceived by IVF. A total of 329 replies were received - 230 via postal contact and 99 by telephone contact. Of the total 329 replies, 169 were from ICSI parents, and 164 from IVF parents.

One family replied by post from New Zealand, and another from Ireland. One family in Ireland were contacted by telephone.

$86(26 \%)$ parents who responded appeared to have concerns and 243 responders appeared to have no concerns. From the responses of the 86 responders who had concerns (45 ICSI parents and 41 IVF parents) 28 different question themes (106 questions in total, see Table 1) were identified. The most common question (25\%) was concerned with their child's future fertility (Fig. 2). Other common themes were related to telling their child of his/her conception (11/86), and to unspecified general health concerns. The two groups (ICSI vs IVF) asked similar questions, but with different frequencies (Tables 2 and 3).

The majority of parents that replied (295/329) indicated that they would be willing to participate in future studies. Only 9 families definitely preferred to not participate in further studies. Most felt that monitoring growth and development as well as general health problems were important (256/329); but some (10/329) felt that growth

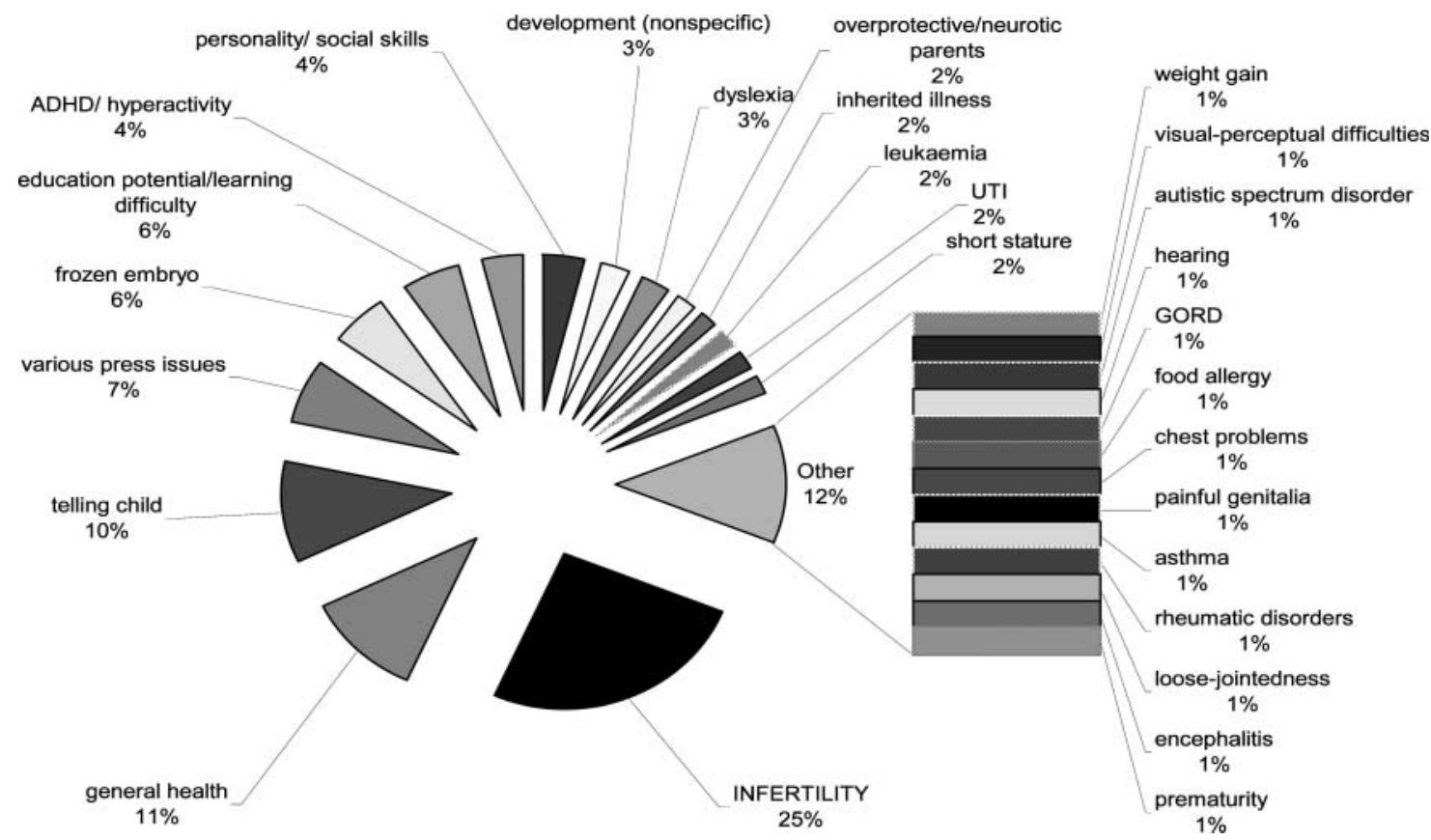

Figure 2 Questions asked by parents whose children were conceived by assisted reproductive therapy. 
Table 2 Questions asked by ICSI parents.

\begin{tabular}{lccc}
\hline Question theme & Number & \% Total ICSI parents (169) & \% Total ICSI parents with questions (45) \\
\hline Their child's future fertility & 20 & $12 \%$ & $44 \%$ \\
General health & 4 & $2 \%$ & $8 \%$ \\
How to tell the child & 6 & $3.5 \%$ & $13 \%$ \\
Education potential/learning difficulty & 3 & $2 \%$ & $6.60 \%$ \\
ADHD/hyperactivity & 3 & $2 \%$ & $6.60 \%$ \\
Dyslexia & 3 & $2 \%$ & $6.60 \%$ \\
Development (non-specific) & 2 & $1 \%$ & $4 \%$ \\
Anxieties raised by press articles & 1 & $0.6 \%$ & $2 \%$ \\
Personality/social skills & 1 & $0.6 \%$ & $2 \%$ \\
Short stature & 1 & $0.6 \%$ & $2 \%$ \\
Weight gain & 1 & $0.6 \%$ & $2 \%$ \\
Visual-perceptual difficulties & 1 & $0.6 \%$ & $2 \%$ \\
Autistic spectrum disorder & 1 & $0.6 \%$ & $2 \%$ \\
Hearing & 1 & $0.6 \%$ & $2 \%$ \\
Food allergy & 1 & $0.6 \%$ & $2 \%$ \\
Painful genitalia & 1 & $0.6 \%$ & $2 \%$ \\
Asthma & 1 & $0.6 \%$ & $2 \%$ \\
Loose-jointedness & 1 & $0.6 \%$ & $2 \%$ \\
Encephalitis & 1 & $0.6 \%$ &
\end{tabular}

Table 3 Questions aksed by IVF parents.

\begin{tabular}{|c|c|c|c|}
\hline Question theme & Number & \% Total IVF parents (164) & $\%$ Total IVF parents with questions (41) \\
\hline Their child's future fertility & 7 & $4 \%$ & $17 \%$ \\
\hline General health & 8 & $5 \%$ & $19.50 \%$ \\
\hline How to tell the child & 5 & $3 \%$ & $12 \%$ \\
\hline Anxieties raised by press articles & 6 & $3.6 \%$ & $14.60 \%$ \\
\hline Risks of embryo cryopreservation & 6 & $3.6 \%$ & $14.60 \%$ \\
\hline Education potential/learning difficulty & 3 & $2 \%$ & $7 \%$ \\
\hline Personality/social skills & 3 & $2 \%$ & $7 \%$ \\
\hline Are ART parents overprotective & 2 & $1 \%$ & $5 \%$ \\
\hline Genetic disorders & 2 & $1 \%$ & $5 \%$ \\
\hline Leukaemia & 2 & $1 \%$ & $5 \%$ \\
\hline Urinary tract infection & 2 & $1 \%$ & $5 \%$ \\
\hline Development (non-specific) & 1 & $0.6 \%$ & $2 \%$ \\
\hline ADHD/hyperactivity & 1 & $0.6 \%$ & $2 \%$ \\
\hline Short stature & 1 & $0.6 \%$ & $2 \%$ \\
\hline GORD & 1 & $0.6 \%$ & $2 \%$ \\
\hline Chest problems & 1 & $0.6 \%$ & $2 \%$ \\
\hline Rheumatic disorders & 1 & $0.6 \%$ & $2 \%$ \\
\hline Prematurity & 1 & $0.6 \%$ & $2 \%$ \\
\hline
\end{tabular}

and development was more important that general health, or (8/329) that monitoring for general health problems was more important than growth and development.

\section{Discussion}

The response rate $(90 \%)$ suggests that parents are interested and motivated to continue participating in the National Child Development Study. 74\% of parents that responded appeared to have no concerns, only $26 \%$ of parents that responded chose to ask additional questions.

The most frequently asked question was whether or not their child conceived using ICSI or IVF would have fertility problems themselves. This was posed in various different ways by 27 ( $8 \%$ all responders) families (7 IVF and 20 ICSI).
The parents who had undergone the more invasive ICSI treatment were 2.5 times more likely to ask this (20 out of the 45 with questions; 44\%) than standard IVF parents (7 out of 41 with questions; $17 \%$ ).

Both groups had concerns about how, when, or if to tell their child about how they had been conceived. 6/45 ICSI $(13 \%)$ and 5/41 IVF (12\%) asked this. Many asked if a booklet or video was available to help them break the news. Members of the study group have actually produced a booklet which was developed with input from some ART parents. We plan to make this available to our study group on request.

One of the more striking observations was that families have asked about a number of different health conditions, most of which (food allergy, asthma, dyslexia, ADHD, etc.) are unlikely to be due to ART per se. Each of those 
families received individual responses. These questions must reflect the strong commitment to parenting that these families have, and their understandable anxiety that any disease or condition their child gets could be related to their assisted conception.

\section{Conclusions}

Parents have unmet information needs about their child's future fertility and any impact that assisted conception may have on their child's future health. They demonstrate a willingness to continue participating in studies and it would seem that this is partly motivated by their concerns about their child's long-term outcome.

These families feel like 'winners in a lottery' (Barnes et al. 2004). They are grateful for any research into the long-term health and wellbeing of their child(ren).

They are keen to find out what has been looked into by other groups and to hear the results of our National Child Development Study. We intend to continue conducting research in this area, to inform these parents and the clinicians looking after them and future generations of assisted conception families.

\section{Acknowledgements}

We are grateful to all the families who have continued to take part in studies. Their high level of commitment is a good motivation to continue exploring the outcome of assisted conception. We would also like to thank clinicians throughout the UK who have been supportive of our work and have been acknowledged in previous papers referenced below. (Sutcliffe et al. 1999, 2001, Bonduelle et al. 2005)

Part of this work was presented at the British Fertility Society annual meeting in April 2004 and was awarded the prize for 'best abstract for counselling and psychosocial aspects of infertility and reproductive medicine'. While no explicit funding was received for this study, generous donations have been received from IBSA biochemique, Switzerland, Serono UK and Ferring UK. The Authors declare that there is no conflict of interest that would prejudice the impartiality of this scientific work.

\section{References}

Barnes J, Sutcliffe AG, Kristofferson I, Loft A, Wennerholm U, Tarlatzis BC, Kantaris X, Nekkebroeck J, Hagberg BS, Madsen SV \& Bonduelle M 2004 The influence of assisted reproduction on family functioning and children's socio-emotional development: results from a European study. Human Reproduction 19 1480-1487.

Bonduelle M, Wennerholm UB, Loft A, Tarlatzis BC, Peters C, Henriet S, Mau C, Victorin-Cederquist A, Van Steirteghem A, Balaska A, Emberson JR \& Sutcliffe AG 2005 A multi-centre cohort study of the physical health of 5-year-old children conceived after intracytoplasmic sperm injection, in vitro fertilization and natural conception. Human Reproduction 20 413-419.

Brewaeys A, Golombok S, Naaktgeboren N, de Brgyn JK \& van Hall EV1997 Donor insemination: Dutch parents' opinions about con- fidentiality and donor anonymity and the emotional adjustment of their children. Human Reproduction 12 1591-1597.

Coleman JC \& Hendry L 1990 The Nature of Adolescence, 3rd edn. London: Routledge.

Colpin H \& Soenen S 2002 Parenting and psychosocial development of IVF children: a follow-up study. Human Reproduction 17 $1116-1123$

Colpin H 2002 Parenting and Psychosocial development of IVF children: Review of the research literature. Developmental Review 22 644-673.

Eugster A \& Vingerhoets AJJM 1999 Psychological aspects of in vitro fertilization: a review. Social Science and Medicine $\mathbf{4 8}$ 575-589.

Fasouliotis SJ \& Schenker JG 1999 Social aspects in assisted reproduction. Human reproduction 5 26-29.

Gibson FL, Ungerer JA, Tennant CC \& Saunders DM 2000a Parental adjustment and attitudes to parenting after in vitro fertilization. Fertility and Sterility 73 565-574.

Gibson FL, Ungerer JA, McMahon CA, Leslie GI \& Saunders DM 2000 The Mother-Child Relationship Following In Vitro Fertilisation (IVF): Infant Attachment, Responsivity, and Maternal Sensitivity. Journal of Child Psychology and Psychiatry 41 1015-1023.

Golombok S, Cook R, Bish A \& Murray C 1995 Families created by the new reproductive technologies: qualitative parenting and social and emotional development of the children. Child Development 66 285-298.

Golombok S, Brewaeys A, Cook R, Giavazzi MT, Guerra D, Mantovani A, van Hall E, Crosignani PG \& Dexeus S 1996 The European study of assisted reproduction families: family functioning and child development. Human Reproduction 11 2324-2331.

Golombok S, MacCallum F \& Goodman F 2001 The 'test-tube' Generation: Parent-Child relationships and the psychological wellbeing on in vitro fertilization children at adolescence. Child Development 72599.

Golombok S, Brewaeys A, Giavazzi MT, Guerra D, MacCallum F \& Rust J 2002 The European study of assisted reproduction families: the transition to adolescence. Human Reproduction 17 830-840.

Golombok S, Lycett E, MacCallum F, Jadva V, Murray C, Rust J, Abdalla H, Jenkins J \& Margara R 2004 Parenting infants conceived by gamete donation. Journal of Family Psychology 18 443-452.

Golombok S, Jadva V, Lycett E, Murray C \& MacCallum F 2005 Families created by gamete donation: follow-up at age 2. Human Reproduction 20 286-293.

Greenfeld DA, Ort SI, Greenfeld DG, Jones EE \& Olive DL 1996 Attitudes of IVF parents regarding the IVF experience and their children. Journal of Assisted Reproduction and Genetics 13 266-274.

Hahn CS \& DiPietro J 2001 In vitro fertilization and the family: Quality of parenting, family functioning, and child psychosocial adjustment. Developmental Psychology 37 37-48.

Hoopes JL 1990 Adoption and identity information. In The psychology of adoption, pp 336-339. Ed. DMS Brodzinsky. Oxford: Oxford University Press.

Lycett E, Daniels K, Curson R \& Golombok S 2004 Offspring created as a result of donor insemination: a study of family relationships, child adjustment, and disclosure. Fertility and Sterility 82 172-179.

Lycett E, Daniels K, Curson R \& Golombok S 2005 School-aged children of donor insemination: a study of parents' disclosure patterns. Human Reproduction 20 810-819.

McMahon CA, Ungerer JA, Beaurepaire J, Tennant C \& Saunders D 1997a Anxiety during pregnancy and fetal attachment after in-vitro fertilization conception. Human Reproduction 12 176-182.

McMahon CA, Ungerer JA, Tennant C \& Saunders D 1997b Psychosocial adjustment and the quality of the mother-child relationship at four months postpartum after conception by in vitro fertilization. Fertility and Sterility 68 492-500.

McMahon CA, Gibson F, Leslie G, Cohen J \& Tennant C 2003 Parents of 5-year-old in vitro fertilisation: psychological adjust- 
ment, parenting stress, and the influence of subsequent in vitro fertilisation treatment. J Fam Psycho 17 361-369.

Peters C, Kantaris X, Barnes J \& Sutcliffe AG 2005 Parental attitudes towards disclosure of the mode of conception to their in-vitro fertilisation IVF - conceived child. Fertility and Sterility 83 914-919.

Pullan-Watkins K 1997 Parent-child attachment: A guide to research. In Reference books on family issues, Vol II, pp 388. New York: Garland reference library on Social Science.

Sutcliffe AG, Taylor B, Li J, Thornton S, Grudzinkas JG \& Lieberman BA 1999 Children born after intracytoplasmic sperm injection: population control study. British Medical Journal 318 704-705.

Sutcliffe AG, Taylor B, Saunders K, Thornton S, Lieberman BA \& Grudzinkas JG 2001 Outcome in the second year of life after in-vitro fertilisation by intracytoplasmic sperm injection: a UK case control study. Lancet 357 2080-2084.

Sutcliffe AG, Barnes J, Wennerholm U-B, Loft A, Tarlatzis BC, PonjaertKristoferson I \& Bonduelle M 2005 Laterality in five-year-olds conceived by intracytoplasmic sperm injection, standard in vitro fertilization and natural conception: a European study. BJOG 112 1-5.

Received 13 June 2005

First decision 5 August 2005

Revised manuscript received 6 September 2005

Accepted 14 September 2005 